\title{
Aging and Cancer Vaccines
}

\author{
Claudia Gravekamp* \& Dinesh Chandra
}

Albert Einstein College of Medicine, Department of Microbiology and Immunology, 1300 Morris Park Avenue, Bronx, New York 10461, USA

*Address all correspondence to: Claudia Gravekamp, Ph.D., Albert Einstein College of Medicine, Department of Microbiology and Immunology, 1300 Morris Park Avenue, Forchheimer Bldg, Room 407A, Bronx, NY 10461; Phone: 718-430-4048 (office) -4067 (lab); Fax: 718-430-8711; E-mail: claudia.gravekamp@einstein.yu.edu

\begin{abstract}
Cancer vaccination is less effective at old than at young age, due to $\mathrm{T}$ cell unresponsiveness. This is caused by age-related changes of the immune system. Major immune defects at older age are lack of naïve $\mathrm{T}$ cells, impaired activation pathways of $\mathrm{T}$ cells and antigen-presenting cells (APC), and age-related changes in the tumor microenvironment (TME). Also innate immune responses are affected by aging, but this seems less abundant than adaptive immune responses. In this review we compared various cancer vaccine studies at young and old age, demonstrating the importance of both innate and adaptive immune responses for cancer immunotherapy. Moreover, we found suggestive evidence that innate immune responses could help improve adaptive immune responses through cancer vaccination in old age.
\end{abstract}

KEY WORDS: cancer vaccination; aging; T cell unresponsiveness; innate immune responses; adaptive immune responses; Listeria monocytogenes

\section{ABBREVIATIONS}

APC: Antigen-presenting cell; $\alpha$ GC: Alphagalactosylceramide; COX: Cyclooxygenase; CTL: Cytotoxic T lymphocytes; DC: Dendritic cell; GM-CSF: Granulocyte macrophage colony-stimulating factor; IDO: Indolamine 2,3-dioxygenase; IL: Interleukin; iNOS:Inducible nitric oxide synthetase; IFN: Interferon; LPS: Lipopolysaccharide; MAGE: Melanoma-associated antigen; MDSC: Myeloid-derived suppressor cells; MHC: Major histocompatibility complex; MLN: Mesenteric lymph nodes; NK: Natural killer; NKT: Natural killer T; PBNC: Peripheral blood mononuclear cells; PGE2: Prostaglandin E2; PPD: Purified protein derivate; PRR: Pattern recognition receptors; ROS: Reactive oxygen species; TAA: Tumor-associated antigen; TAM: Tumor-associated macrophages; TCR: T cell receptor; TGF: Transforming growth factor; TLR:Toll-like receptor; TME: Tumor microenvironment; TNF: Tumor necrosis factor; Tregs: T regulatory cells; VGEF: Vascular endothelial growth factor

\section{INTRODUCTION}

Cancer is most common among the elderly. With the increase in the elderly population, we can expect an increase in the number of cancer patients and mortality. While primary tumors can often be removed by surgery, followed by radiation, chemo-, or adjuvant therapy, for metastases there is no cure. ${ }^{1}$ In contrast, cancer vaccination targeting tumorassociated antigens (TAA) shows great promise against metastases ${ }^{2-4}$ but a major problem mostly overlooked in clinical trials is the importance of the age factor in cancer immunotherapy, i.e., vaccines are less effective at old than at young age. ${ }^{5-7}$ This is caused by major age-related defects in immune responses, resulting in short-lasting and weak $\mathrm{T}$ cell responses to TAA. Analysis of various vaccine studies in preclinical cancer models at young and old age showed that most anti-tumor innate responses could be obtained by tailoring vaccination to older age, while $\mathrm{T}$ cell responses were hardly detectable. Therefore, we questioned whether innate immune responses could be used to improve adaptive $\mathrm{T}$ cell responses at older age. To answer this question, we reviewed adaptive and innate immune responses in elderly and cancer patients, and compared vaccine studies in preclinical models at young and old age. Based on these studies, new approaches to improve innate and adaptive immune responses against cancer through immunotherapy at older age are proposed. 


\section{IMMUNE DEFECTS AT OLDER AGE}

\section{A. Adaptive Immune Responses}

Unresponsiveness of $\mathrm{T}$ cells at older age is caused by various age-related changes of the immune system. One of the most consequential changes in the immune system is lack of naïve $\mathrm{T}$ cells (i.e., cells that react for the first time to new antigens) and an increase in the number of memory $\mathrm{T}$ cells (i.e., cells that react to previously encountered antigens) at old compared to young age. It has been suggested that continual activation of the immune system by new antigens during the life span would lead to a depletion of naive $\mathrm{T}$ cells from the thymus, and a clonal expansion of memory $\mathrm{T}$ cells. ${ }^{8}$ With the involution of the thymus being almost complete at the age of 60 years, new naïve $T$ cells at old age can no longer be generated. ${ }^{9}$ The host is then dependent on the pool of naïve $\mathrm{T}$ cells generated earlier in life. Analogous to the situation in humans, a decrease of naive $\mathrm{T}$ cells and an increase of memory $\mathrm{T}$ cells have also been described for aging mice. ${ }^{9}$ Other possible causes for diminished $T$ cell responses in aged humans and mice have been described, such as defects in T cell receptor (TCR)/CD3-mediated phosphorylation events or aberrant regulation of tyrosine kinases associated with the $\mathrm{TCR}^{10}$ and a decrease in $\alpha \beta$ repertoire of the TCR. ${ }^{11}$ The TCR is expressed by T cells, and is required for recognition of foreign antigens in association with self-major-histocompatibility complex (MHC) molecules, presented by antigenpresenting cells (APC) to the immune system, and for subsequent activation of $T$ cells. Another molecule important for $\mathrm{T}$ cell activation is $\mathrm{CD} 28$, which is expressed at the cell membrane of T cells, and is the ligand for co-stimulatory molecule B7, expressed on APC. Clinical studies have documented that high proportions of CD8 T cells that lack CD28 are correlated with reduced antibody response to influenza vaccination. ${ }^{12}$ Also in mice, CD8 $\mathrm{T}$ cells lacking CD28 expression have been reported. ${ }^{13}$ Moreover, it has been shown that CD28-lacking CD8 T cells can suppress antigen-specific CTL responses. ${ }^{14}$

In addition to $\mathrm{T}$ cell impairments, defects in cytokine production have also been observed in aged humans as well. An example is a human vaccine study in which significantly lower interleukin (IL)-2 was produced by $\mathrm{T}$ cells of older individuals stimulated with an influenza vaccine in vitro compared to those of young individuals. ${ }^{5}$ Similarly, significantly lower interferon (IFN) $\gamma$ was produced by peripheral blood mononuclear cells (PBMC) from elderly individuals immunized with an influenza vaccine compared to young individuals. IL-2 promotes $\mathrm{T}$ cell activation and proliferation, as well as release of IFN $\gamma$ by $\mathrm{T}$ cells. The lower IL-2 production following in vitro stimulation with the influenza vaccine may explain the lower IFN $\gamma$ production. IFN $\gamma$ is also involved in activation of dendritic cells (DC). These DC are important for cytotoxic $\mathrm{T}$ lymphocyte (CTL) priming.

\section{B. Innate Immune Responses at Older Age}

Although the innate immune system is affected by aging as well, the changes seem less dramatic than those observed in the adaptive immune system. This branch of immunity includes natural killer (NK) cells, natural killer T (NKT) cells, gd T cells, dendritic cells, macrophages, and neutrophils. NK cells respond as first line defense against infections and cancer. Their function has been extensively analyzed in relation to aging in humans and mice. Although NK cell function and number are decreased in old compared to young mice (such as the production of IFNg, IL-2 or perforin) in healthy human centenarians NK cell cytotoxicity and production of IL-12, IFNa, and IFNg is well preserved, but somewhat decreased in the less healthy elderly. ${ }^{15}$ In our own studies, we observed that the production of IFNg by NK cells induced by vaccination with an attenuated Listeria monocytogenes was almost at the same level in old as in young mice. ${ }^{16}$

NKT cells belong to the innate immune system because of their early response to infection and cancer. Although NKT cells have certain characteristics of $\mathrm{T}$ cells, they share several functional and phenotypic features with NK cells. ${ }^{17}$ They represent a heterogeneous population of CD4+, CD8+, or CD4- 
CD8- cells, but most characteristic of NKT cells is their invariant TCR Va14Ja281/Vb8.2, or Vb7, or $\mathrm{Vb} 2$ in mice and $\mathrm{Va} 24 \mathrm{JaQ} / \mathrm{Vb} 11$ in humans. While the number of NKT cells increases with age, their production of Th1 cytokines decreases with age. ${ }^{18}$ However, NKT cells bearing TCRgd strongly increase with age and their functions are well preserved in very old mice and humans. ${ }^{19}$ When activated with a-galactosylceramide (aGC), NKT cells communicate with NK cells through the production of cytokines. ${ }^{20}$

DCs are affected by aging. They play an important role in $\mathrm{T}$ cell activation, but the age-related effects on DC described are variable. It has been reported that blood DC from old individuals can still function as powerful antigen-presenting cells when exposed to purified protein derivate (PPD) of Mycobacterium tuberculosis or influenza vaccine, ${ }^{21}$ while others have shown that DCs from aged individuals are more mature and have impaired ability to produce IL-12, ${ }^{22}$ or that secretion of tumor necrosis factor (TNF)a and IL-6 significantly increased upon stimulation with lipopolysaccharide (LPS) and ssRNA in DC of aged compared to young individuals. ${ }^{23}$ Still other reports claim that no major effects on the numbers of DC were observed by aging, but their capacity to phagocytose antigens and migration was impaired with age. ${ }^{24}$

Macrophages play an important role in the clearance of infections. Cross talk between innate and adaptive immune responses exists through shared receptors such as the family of Toll-like receptors (TLR). It has been reported that Toll-like receptor (TLR) signaling in macrophages is defective at older age. ${ }^{25,26} \mathrm{Also}$, aging in mice has been associated with an increase in the number of bone marrow macrophages that have an impaired ability to respond to infections, while cytokines such as circulating IL-6 or IL-10 increases with age upon stimulation with LPS. ${ }^{27,28}$

Myeloid-derived suppressor cells (MDSC) migrate from the bone marrow into the blood circulation during infections or cancer. They are a heterogeneous population of myeloid progenitor cells, i.e., immature macrophages, granulocytes, and dendritic cells (DCs) that are endowed with robust immunosuppressive activity. ${ }^{29,30}$ Evidence exists that the number of MDSC in blood increases with age. ${ }^{31}$ Influenza infection is a major problem in the elderly because their immune system is significantly impaired compared to young adults. It has been shown that MDSC accumulate in the lung in response to influenza $A$ virus infections, and correlates with suppression of CD4 $\mathrm{T}$ cell responses, which negatively influences the course of the disease. ${ }^{32}$ The higher number of MDSC at older age may contribute to the decreased ability of elderly persons to clear the viral infection. We found that MDSC play a central role in cancer immunotherapy and could be used to improve $\mathrm{T}$ cell responses by Listeria-based vaccination at young and old age. ${ }^{16}$ (For more details see "Cancer Vaccination in the Elderly.")

\section{IMMUNE DEFECTS IN CANCER PATIENTS}

\section{A. Adaptive Immune Responses}

In cancer patients CTL-recognizing TAA in association with major histo-compatibility complex (MHC) molecules on the tumor cells through their $\mathrm{T}$ cell receptor, and expected to destroy tumor cells when exposed simultaneously to both TAA/selfMHC complexes and co-stimulatory moleculesare often found at the site of the tumor, but have evidently been unable to destroy the tumor cells. ${ }^{33}$ Multiple possible causes have been described for this unresponsiveness of the CTL in cancer patients (for a review see Gravekamp ${ }^{6}$ ). This includes decreased expression of MHC, TAA, or co-stimulatory molecules by tumor cells, and immune suppression induced by the primary tumors. In humans and mice, many tumors secrete lymphokines or factors that inhibit vaccine-induced T cell and NK cell responses. Examples are transforming growth factor (TGF) $\beta$, IL-6, IL-10, cyclooxygenase-2 (COX-2), and its products prostaglandin $\mathrm{E} 2\left(\mathrm{PGE}_{2}\right), \mathrm{PD} 1$-ligand, or indolamine 2,3-dioxygenase (IDO). ${ }^{34}$

$T$ regulatory cells $\left(\mathrm{T}_{\text {regs }}\right)$ are a component of the immune system that suppresses immune responses of other cells. This may happen after infections or to prevent autoimmunity, but also in cancer patients to prevent the tumor cells from being killed by cells 
of the immune system, through the production of soluble factors such as IL-10 and TGF $\beta$ or through direct cell-cell contact, resulting in the inhibition of T cell and NK cell responses. ${ }^{35-40}$ Moreover, evidence exists that the number of $\mathrm{T}_{\text {regs }}$ increases with age, but not their function. ${ }^{40}$

\section{B. Innate Immune Responses}

Cells of the innate immune system play an important role in the TME. For instance, MDSC suppress $\mathrm{T}$ cell and NK cell responses by the production of IL-6, IL-10, TGF $\beta$, reactive oxygen species (ROS), inducible nitric oxide synthase (iNOS), or arginase ${ }^{29,30}$ and contribute to the expansion of regulatory $\mathrm{T}$ cells $\left(\mathrm{T}_{\text {regs }}\right)$ in the TME. ${ }^{41}$ Furthermore, tumor-associated macrophages (TAM) and M2 macrophages strongly suppress $\mathrm{T}$ cell responses through the production of IL-6, IL-10, and TGF $\beta$ in the TME. ${ }^{42}$ Interestingly, it has been reported that the TME changes with age, i.e., it appeared that the number of MDSC in the TME increases with age, and contributes to the $\mathrm{T}$ cell unresponsiveness at older age. ${ }^{43}$ However, to date, minimal research has been performed on MDSC and $\mathrm{T}$ cell unresponsiveness in relation to aging. Our laboratory has analyzed MDSC in mice with metastatic breast cancer and found that the number of MDSC was five times higher in old than in young mice. ${ }^{16}$ Because of their high number in patients and mice with cancer, and because of their central role in immune suppression in the TME, particularly at old age, MDSC are highly attractive for use in cancer immunotherapy. Importantly, our studies show that MDSC play a central role in Listeria-based cancer immunotherapy at young and old age ${ }^{16}$ (for more details see below under "Cancer Vaccination in the Elderly").

In vivo depletion of NK cells leads to a poor control of tumor growth in various cancer models, indicating the importance of NK cells in anti-tumor responses and tumor surveillance. ${ }^{44-48}$ Evidence exists from mice and humans that although NK cells are affected by aging, they nevertheless still function at older age. However, the effect of aging on NK cells against cancer has been far less extensively studied than T cells. A few reports describe that NK cells of the elderly had a lower ability to respond to IL-2, lower spontaneous cytolytic activity towards tumors than young adults. ${ }^{19}$ However, NK cells can also be used to kill tumor cells through pathways distinct from perforin-mediated tumor cell destruction. For instance, a clinical trial is ongoing with bortezomib which sensitizes tumor cells for TRAIL- and FasLmediated destruction by NK cells in cancer patients between 20 and 70 years (NCT00720785). ${ }^{48} \mathrm{We}$ found NK cell responses (producing IFN $\gamma$ ) in vivo in old mice with metastatic breast cancer after vaccination with pcDNA3.1-Mage-b. ${ }^{49}$ Also NKT cells have anti-tumor activity in mice, including lung and hepatic cancer metastases when activated by $\alpha \mathrm{Gal}-$ Cer, by secreting large amounts of IFN $\gamma$ and IL-4, resulting in activation of other cells of the immune system, including NK cells. ${ }^{50,51}$ In a phase I clinical trial with $\alpha \mathrm{GalCer}$ in patients with solid tumors, the effect was dependent on the high number of NKT cells present pretreatment. ${ }^{52}$ Since the number of NKT cells increases with age and have anti-tumor reactivity, $\alpha \mathrm{GalCer}$ could be a potential candidate to activate NKT cells against cancer at older age.

\section{CANCER VACCINATION IN THE ELDERLY}

More than $50 \%$ of all cancer patients are 65 years or older. The vaccine studies discussed below show that cancer vaccination is less effective at old than at young age, but that tailoring cancer vaccination to older age is feasible. Moreover, innate immune responses may be a potential target for improving immunotherapy against cancer at older age.

Provinciali and colleagues reported that immunization with a genetically engineered mammary adenocarcinoma, TS/A-IL-2, protected both young and old mice from TS/A challenge, which was not possible without IL-2. ${ }^{33} \mathrm{CD} 4$ and CD8 T cells were present in tumors of young but hardly detectable in tumors of old mice, while macrophages and neutrophils were detected at both ages. However, protective memory responses that could reject tumor cells upon rechallenge of tumor-free mice was only obtained in young mice. Another study 
by the Provinciali group showed that vaccination with pCMV-neuNT against Her2/neu-expressing breast tumor cells (TUBO) completely protected young mice but only $60 \%$ of the old mice from TUBO challenge, and correlated with proliferation of spleen cells of young compared to old mice, in vitro, upon restimulation with the Her/2 neu antigen. ${ }^{54}$

Lustgarten and colleagues also found that cancer vaccination was less effective at old than at young age. They showed that young but not old mice developed long-lasting memory responses to a pre-B-cell lymphoma (BM-185). However, inclusion of CD80 in the BM-185 cell line (BM-185-CD 80) plus agonist anti-OX-40 or anti-4-1BB (receptor for co-stimulation on $\mathrm{T}$ cells) $\mathrm{mAb}$ induced equally strong long-lasting memory responses at young and old age, suggesting the involvement of $\mathrm{T}$ cells. ${ }^{55} \mathrm{In}$ another study the same group found that adding anti-OX40 or anti-4-1BB $\mathrm{mAb}$ to a $\mathrm{DC}$ vaccine resulted in vigorous anti-tumor responses in a syngeneic TRAMP-C2 model at young and old age, while without anti-OX40 or anti-4-1BB, protection was significantly better in young than in old mice. ${ }^{56}$ Moreover, immunization of young and old mice with DC-TRAMP-C2 vaccine plus anti-OX40 or anti-4-1BB mAb resulted in improved CTL responses to apoptotic TRAMP-C2 cells in vitro upon restimulation, compared to the same vaccination without $\mathrm{OX} 40$ or anti-4-1BB mAb at old age. Nevertheless, the CTL responses were less vigorous compared to the same immunizations at young age.

Studies by Yung and colleagues showed that vaccination with a DC-OVA vaccine derived from young mice was less effective against B16-OVA melanoma tumors in old than in young mice, underscoring the effect of the altered TME at older age on vaccination. ${ }^{57}$ Also the group of Zhang found that the TME was altered at old compared to young age. They demonstrated that the number of myeloidderived suppressor cells (MDSC) increased in the tumor environment of old compared to young mice, and that this contributed to the age-related $\mathrm{T}$ cell unresponsiveness. ${ }^{43}$

Our group developed a DNA vaccine of Mage$\mathrm{b}$ (pcDNA3.1-Mage-b) and tested this vaccine at young and old age in two syngeneic metastatic mouse breast tumor models, $4 \mathrm{TO} 7 \mathrm{cg}$ and $4 \mathrm{~T} 1$, both overexpressing Mage- $b$ in metastases and primary tumors. ${ }^{49}$ Vaccination of both models with Mage-b was highly effective against metastases in young, but not old mice; this correlated with the strong Mage$\mathrm{b}$-specific $\mathrm{T}$ cell responses in vitro and in vivo at young but not at old age. ${ }^{49}$ Interestingly, we found that Mage- $b$ vaccination activated macrophages and NK cells (producing IFN $\gamma$ ) in old mice. ${ }^{49}$ In a more recent vaccine study with Mage-b delivered through highly attenuated Listeria monocytogenes we found a dramatic effect on the metastases in the 4T1 model at young age. ${ }^{58}$ The dramatic effect of Listeria on the metastases was due to an intimate relationship between Listeria, MDSC, and cancer.. We found that Listeria-infected MDSC, selectively migrated to the TME, ${ }^{16,59}$ most likely through attractants such IL-6, granulocyte macrophage colony-stimulating factor (GM-CSF), A100. ${ }^{60}$ Once at the tumor site, Listeria is able to spread from MDSC into tumor cells through a cell-to-cell spread mechanism, characteristic of Listeria, ${ }^{16,59}$ and then kill the tumor cells through high levels of reactive oxygen species (ROS). Moreover, Listeria-infected tumor cells became a highly sensitive target for Listeria-activated $\mathrm{T}$ cells and NK cells. ${ }^{58}$

We also found that Listeria-infected MDSC had equal efficacy at young and old age, indicating that MDSC are an attractive target for Listeria-based immunotherapy at all ages. Indeed, using a semitherapeutic immunization protocol (one immunization before, and two after tumor development) Listeriabased vaccination was equally effective against metastatic breast cancer at young and old age. ${ }^{16} \mathrm{~A}$ nearly complete elimination of the metastatic breast cancer was observed at both ages. We found that Listeria reduced the number of MDSC in blood and primary tumors, and induced IL-12 production in a subpopulation of the remaining MDSC at young and old age. This resulted in strong NK and T cell responses to Listeria at both ages. We concluded that targeting MDSC by Listeria-based immunotherapy is important for improving $\mathrm{T}$ cell responses in young and old mice with metastatic cancer. In other words, the intimate relationship between Listeria, MDSC, and cancer resulted in improved $\mathrm{T}$ cell responses at young and old age. Finally, we developed a more 
clinically relevant therapeutic immunization protocol. Initially, we applied immunizations with high doses of Listeria at 1-week time intervals, but little effect was observed against the tumor and metastases, mainly due to immune suppression in the TME. However, when frequent immunizations with low doses of Listeria were applied every other day, we observed a nearly complete elimination of the metastases. ${ }^{16}$ Whether this correlated with improved innate and adaptive immune responses is currently under investigation.

\section{CONCLUSION AND FUTURE DIRECTIONS}

A major conclusion from the studies analyzed here is that the innate immune system should certainly be considered for testing as a potential candidate for immunotherapy at older age. While the effect of cancer vaccination on growth of tumors and metastases could be strongly improved by tailoring the vaccine to older age, as shown in the preclinical studies analyzed here, in most cases improvement was not the result of $\mathrm{T}$ cell activation but rather the result of other immune cells stimulated by the vaccine. Although various functions of NK and NKT cells are decreased at old age, it is significantly less dramatic than the age-related decline in $\mathrm{T}$ cell function, and both cells play an important role in anti-tumor responses. Improvement of $\mathrm{T}$ cell activation against cancer through vaccination at older age should also be further optimized. Below, new strategies to improve adaptive and innate immune responses against cancer at older age through vaccination or immunotherapy, respectively, are proposed below and summarized in Fig. 1.

As mentioned above, innate immune responses should be considered as a potential target for improvement of immunotherapy against cancer at older ages. For instance, NK cells and TCR $\gamma \delta$ NKT cells could be activated by attenuated Listeria and/or $\alpha \mathrm{GalCer}$ and exhibit anti-tumor activity. Since the number of TCR $\gamma \delta$ NKT and NK cells also increases with age, Listeria-based vaccination in combination with $\alpha \mathrm{GalCer}$ could enhance vaccine-induced $\mathrm{T}$ cell responses against cancer at older age. Improved innate immune responses may lead to improved adaptive immune responses.

MDSC play a major role in immune suppression in the TME, particularly at old age. In addition to Listeria, CpG ODN, vitA, and several chemotherapeutics may decrease the number or polarize MDSC into an immune-stimulating phenotype ${ }^{61}$ It has been shown that $\mathrm{CpG}$ and Listeria seem to be particularly effective at enhancing cellular and/or humoral immunity and promoting Th1-type responses in old mice. ${ }^{16,62}$ Immune suppression in the TME is often induced by cytokines and factors produced by MDSC and the tumor cells. For instance, IL-6 is a cytokine produced by many cancers, MDSC, and tumor-associated macrophages (TAM), and strongly suppresses $\mathrm{T}$ cell responses in the TME. Moreover, IL-6 recruits MDSC to the TME. We have shown that curcumin, an Indian spice with antiinflammatory properties, improved vaccine efficacy of Listeria-Mage-b through reduced IL-6 production and improved $\mathrm{T}$ cell responses to Mage- $\mathrm{b}$ in young mice. ${ }^{63}$ Since the IL-6 production and the MDSC population increases with age, a similar approach might reduce the $\mathrm{T}$ cell unresponsiveness in the TME also at old age.

$\mathrm{T}$ cells could also be activated through other strategies. For instance, the problem of lack of naïve $\mathrm{T}$ cells, one of the most important changes at older age, could be avoided by immunizing at young age when sufficient naïve $T$ cells are present and boosted to generate memory $\mathrm{T}$ cells, followed by recall at old age to reactivate memory $T$ cells. Such an approach has been successfully used for improving antibody production at older age. ${ }^{64}$ Also, naïve $\mathrm{T}$ cells could be recruited by IL-7 at older age. ${ }^{65}$ However lack of naive $T$ cells is not the only hurdle to overcome. TAA are weakly immunogenic and $\mathrm{T}$ cells need help to become activated against TAA expressed by cancer cells. As shown in the studies discussed here, just adding IL-2 to TS/A tumor cells improves anti-tumor responses but not memory responses to the tumor at old age. Thus far, the best results have emerged from studies by the Lustgarten group, which involved activating $\mathrm{T}$ cells against cancer through vaccination plus co-stimulation using anti-OX40 or 


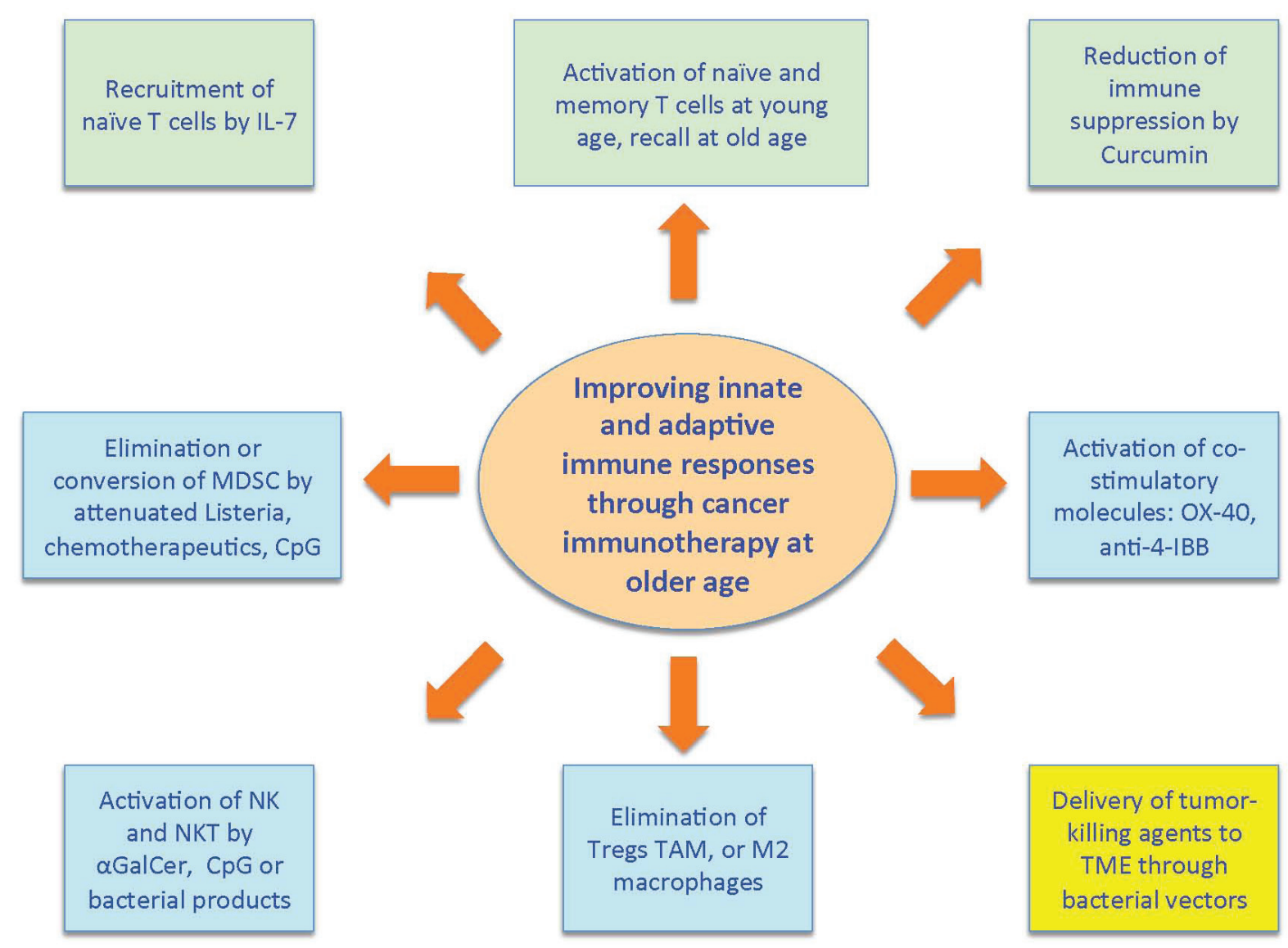

FIGURE 1. Improvement of innate and adaptive immune responses through cancer immunotherrapy. Various approaches are proposed that may improve innate immune responses and subsequently adaptive immune responses through cancer immunotherapy at older age. This includes activation of innate immune responses (blue boxes) by elimination or conversion of myeloid-derived suppressor cells (MDSC) through attenuated Listeria, chemotherapeutics, or $\mathrm{CpG}$, or activation of co-stimulatory molecules through OX-40 or anti-4-IBB, or elimination of $\mathrm{T}_{\text {regs, }}$ tumor-associated macrophages (TAM) or M2, or activation of NKT cells and NK cells through alphagalactosylceramide ( $\alpha \mathrm{GalCer}$ ) or bacterial products. As discussed, activation of the innate immune responses may lead to improved T cell responses. However, there are also other approaches (green boxes) that may lead to improved T cell responses at older age, such as addressing the lack of naïve $T$ cells by recruiting naïve $T$ cells through interleukin (IL)-7, or generating memory $T$ cells at young age and recalling these memory $T$ cells at old age, or by reducing immune suppression by IL-6, which is increased particularly at old age. Finally, we included one complete different approach (yellow box) that ultimately may lead to less immune suppression, i.e., killing tumor cells by delivery of anti-cancer agents through bacterial vectors. Treatment of pancreatic cancer with radioactive Listeria is a great example because it had a great effect on pancreatic cancer. If the growth of tumor and metastases are strongly reduced by such treatment, immune suppression will be at its lowest point, and application of cancer immunotherapy will be more successful. 
$1-4 \mathrm{BB} \mathrm{mAb}$ at young and old age. Elimination of $\mathrm{T}_{\text {regs }}$ might further improve $\mathrm{T}$ cell activation at older age.

Other types of approaches might be used to fight metastatic cancer at young and old age. We have shown that an attenuated Listeria monocytogenes with help of MDSC can be used to deliver tumorkilling agents, such as radioactivity, selectively to the metastases and tumor in a mouse model of pancreatic cancer. ${ }^{59}$ This resulted in an almost complete elimination of the pancreatic tumor, without severe side effects. This was possibly due to that fact that low doses of radioactivity, through the selective delivery of radioactivity by Listeria with help of the MDSC to the TME, were sufficient to kill the tumor cells without harming normal tissues. Other nonpathogenic bacteria are currently under investigation for the delivery of tumor-killing agents selectively into tumor cells such as Lactococcus lactis and E. coli. ${ }^{66,67}$ Our results suggest that such an approach could be effective at both young and old age. If metastases and tumors are mostly eliminated by such treatment, immune suppression will be at its lowest point and follow-up with a targeted immunotherapy will greatly profit from the lower immune suppressive TME.

In summary, despite numerous obstacles that need to be overcome, vaccination against cancer is potentially the most promising approach. While cancer vaccines have limited success against late stage tumor development, they can be particularly effective in situations where almost all other therapies fail,i.e., against metastases and recurrence of cancer. The vaccine studies analyzed here show that improvement of vaccine efficacy at older age is possible, but that, in addition to activation of $\mathrm{T}$ cells, the innate immune system also should be considered as an important target for immunotherapy against cancer at older age. Finally, the results of these studies demonstrate the need of testing and tailoring cancer vaccines to older age in preclinical models before entering the clinic.

\section{ACKNOWLEDGMENTS}

Our work was supported by NIA/NCI grant 1RO1 AG023096-01, training grant NIH1T32 AG23475, The Paul F. Glenn Center for the Biology of Human
Aging Research 34118A, and the Nathan Shock Center for Aging Research (P30AG0380072; Pilot Grant).

\section{REFERENCES}

1. Pardal R, Clarke MF, Morrison SJ. Applying the principles of stem-cell biology to cancer. Nat Rev Cancer. 2003;3:895-902.

2. Kim SH, Castro F, Gonzalez D, Maciag PC, Paterson Y, Gravekamp C. Mage-b vaccine delivered by recombinant Listeria monocytogenes is highly effective against breast cancer metastases, $\mathrm{Br} \mathrm{J}$ Cancer. 2008;99:741-9.

3. Kruit WH, van Ojik HH, Brichard VG, Escudier B, Dorval T, Dreno B, Patel P, van Baren N, Avril MF, Piperno S, Khammari A, Stas M, Ritter G, Lethe B, Godelaine D, Brasseur F, Zhang Y, van der Bruggen P, Boon T, Eggermont AM, Marchand M. Phase 1/2 study of subcutaneous and intradermal immunization with a recombinant MAGE-3 protein in patients with detectable metastatic melanoma. Int J Cancer. 2005;117:596-604.

4. Marchand M, Punt CJ, Aamdal S, Escudier B, Kruit WH, Keilholz U, Hakansson L, van Baren N, Humblet Y, Mulders P, Avril MF, Eggermont AM, Scheibenbogen C, Uiters J, Wanders J, Delire M, Boon T, Stoter G. Immunisation of metastatic cancer patients with MAGE-3 protein combined with adjuvant SBAS-2: a clinical report. Eur J Cancer. 2003;39:70-77.

5. McElhaneyJE, Meneilly GS, Lechelt KE, Bleackley RC. Split-virus influenza vaccines: do they provide adequate immunity in the elderly?. J Gerontol. 1994;49:M37-43.

6. Gravekamp C. The importance of the age factor in cancer vaccination at older age. Cancer Immunol Immunother. 2009;58:1969-1977.

7. Miller RA. The aging immune system: primer and prospectus. Science. 1996;273:70-74.

8. Utsuyama M, Hirokawa K, Kurashima C, Fukayama M, Inamatsu T, Suzuki K, Hashimoto W, Sato $K$. Differential age-change in the numbers of CD4+CD45RA+ and CD4+CD29+ T cell subsets in human peripheral blood. Mech Ageing Dev. 1992;63:57-68. 
9. Grubeck-Loebenstein B. Changes in the aging immune system. Biologicals. 1997;25:205-8.

10. Tamir A, Eisenbraun MD, Garcia GG, Miller RA. Age-dependent alterations in the assembly of signal transduction complexes at the site of T cell/APC interaction. J Immunol. 2000;165:1243-51.

11. Wack A, Cossarizza A, Heltai S, Barbieri D, D'Addato S, Fransceschi C, Dellabona P, Casorati G: Age-related modifications of the human alphabeta $\mathrm{T}$ cell repertoire due to different clonal expansions in the CD4+ and CD8+ subsets. Int Immunol. 1998;10:1281-8.

12. Effros RB: Role of $\mathrm{T}$ lymphocyte replicative senescence in vaccine efficacy. Vaccine. 2007;25: 599-604.

13. Effros RB. Replicative senescence of CD8 T cells: effect on human ageing. Exp Gerontol. 2004;39: $517-24$.

14. Filaci G, Fravega M, Negrini S, Procopio F, Fenoglio D, Rizzi M, Brenci S, Contini P, Olive D, Ghio M, Setti M, Accolla RS, Puppo F, Indiveri F. Nonantigen specific CD8+ T suppressor lymphocytes originate from CD8+CD28- T cells and inhibit both T-cell proliferation and CTL function. Hum Immunol. 2004;65:142-56.

15. Ogata K, Yokose N, Tamura H, An E, Nakamura K, Dan K, Nomura T. Natural killer cells in the late decades of human life. Clin Immunol Immunopathol. 1997;84:269-75.

16. Chandra D, Jahangir A, Quispe-Tintaya W, Einstein $\mathrm{MH}$, Gravekamp C. Myeloid-derived suppressor cells have a central role in attenuated Listeria monocytogenes-based immunotherapy against metastatic breast cancer in young and old mice. $\mathrm{Br}$ J Cancer. 2013;108:2281-90.

17. Emoto M, Kaufmann SH. Liver NKT cells: an account of heterogeneity. Trends Immunol. 2003;24:364-9.

18. Mocchegiani E, Malavolta M. NK and NKT cell functions in immunosenescence. Aging Cell. 2004;3:177-184.

19. Plackett TP, Boehmer ED, Faunce DE, Kovacs EJ. Aging and innate immune cells. J Leukoc Biol. 2004;76:291-9.

20. Biron CA, Brossay L. NK cells and NKT cells in innate defense against viral infections. Curr Opin Immunol. 2001;13:458-64.
21. Sprecher E, Becker Y, Kraal G, Hall E, Harrison D, Shultz LD. Effect of aging on epidermal dendritic cell populations in $\mathrm{C} 57 \mathrm{BL} / 6 \mathrm{~J}$ mice. J Invest Dermatol. 1990;94:247-53.

22. Della Bella S, Bierti L, Presicce P, Arienti R, Valenti M, Saresella M, Vergani C, Villa ML. Peripheral blood dendritic cells and monocytes are differently regulated in the elderly. Clin Immunol. 2007;122:220-8.

23. Agrawal A, Agrawal S, Cao JN, Su H, Osann K, Gupta S. Altered innate immune functioning of dendritic cells in elderly humans: a role of phosphoinositide 3-kinase-signaling pathway.J Immunol. 2007;178:6912-22.

24. Agrawal A, Gupta S. Impact of aging on dendritic cell functions in humans. Ageing Res Rev. 2011;10:336-45.

25. Dunston CR, Griffiths HR. The effect of ageing on macrophage Toll-like receptor-mediated responses in the fight against pathogens. Clin Exp Immunol. 2010;161:407-16.

26. Goral J, Kovacs EJ. In vivo ethanol exposure downregulates TLR2-, TLR4-, and TLR9-mediated macrophage inflammatory response by limiting p 38 and ERK1/2 activation. J Immunol. 2005;174:456-63.

27. Treuting PM, Linford NJ, Knoblaugh SE, Emond MJ, Morton JF, Martin GM, Rabinovitch PS, Ladiges WC. Reduction of age-associated pathology in old mice by overexpression of catalase in mitochondria. J Gerontol A Biol Sci Med Sci. 2008;63:813-22.

28. Wei J, Xu H, Davies JL, Hemmings GP. Increase of plasma IL-6 concentration with age in healthy subjects. Life Sci. 1992;51:1953-6.

29. Gabrilovich DI, Nagaraj S. Myeloid-derived suppressor cells as regulators of the immune system. Nat Rev Immunol. 2009;9:162-74.

30. Ostrand-Rosenberg S, Sinha P. Myeloid-derived suppressor cells: linking inflammation and cancer. J Immunol. 2009;182:4499-506.

31. Verschoor CP, Johnstone J, Millar J, Dorrington MG, Habibagahi M, Lelic A, Loeb M, Bramson JL, Bowdish DM. Blood CD33(+)HLA-DR(-) myeloid-derived suppressor cells are increased with age and a history of cancer. J Leukoc Biol. 2013;93:633-7.

32. Jeisy-Scott V, Davis WG, Patel JR, Bowzard JB, 
Shieh WJ,Zaki SR, Katz JM, Sambhara S. Increased MDSC accumulation and Th2 biased response to influenza A virus infection in the absence of TLR7 in mice. PLoS One. 2011;6:e25242.

33. Gravekamp C, Bontenbal M, Ronteltap CP, Van Duyvenbode $\mathrm{D}$, Bolhuis RL. In vitro and in vivo activation of CD4+ lymphocytes by autologous tumor cells. Int J Cancer. 1990;46:151-2.

34. Gajewski TF, Meng Y, Harlin H. Immune suppression in the tumor microenvironment. J Immunother. 2006;29:233-40.

35. Bluestone JA, Abbas AK. Natural versus adaptive regulatory T cells. Nat Rev Immunol. 2003;3:253-7.

36. Shimizu J, Yamazaki S, Sakaguchi S. Induction of tumor immunity by removing CD25+CD4+ T cells: a common basis between tumor immunity and autoimmunity. J Immunol. 1999;163:5211-8.

37. Tanaka H, Tanaka J, Kjaergaard J, Shu S. Depletion of CD4+ CD25+ regulatory cells augments the generation of specific immune $T$ cells in tumor-draining lymph nodes. J Immunother. 2002;25:207-17.

38. Chen A, Liu S, Park D, Kang Y, Zheng G. Depleting intratumoral $\mathrm{CD} 4+\mathrm{CD} 25+$ regulatory $\mathrm{T}$ cells via FasL protein transfer enhances the therapeutic efficacy of adoptive $\mathrm{T}$ cell transfer. Cancer Res. 2007;67:1291-8.

39. Mahnke K, Schonfeld K, Fondel S, Ring S, Karakhanova S, Wiedemeyer K, Bedke T, Johnson TS, Storn V, Schallenberg S, Enk AH. Depletion of $\mathrm{CD} 4+\mathrm{CD} 25+$ human regulatory $\mathrm{T}$ cells in vivo: kinetics of Treg depletion and alterations in immune functions in vivo and in vitro. Int J Cancer. 2007;120:2723-33.

40. Gregg R, Smith CM, Clark FJ, Dunnion D, Khan $\mathrm{N}$, Chakraverty R, Nayak L, Moss PA. The number of human peripheral blood CD4+ CD25high regulatory $\mathrm{T}$ cells increases with age. Clin Exp Immunol. 2005;140:540-6.

41. Schlecker E, Stojanovic A, Eisen C, Quack C, Falk CS, Umansky V, Cerwenka A: Tumor-infiltrating monocytic myeloid-derived suppressor cells mediate CCR5-dependent recruitment of regulatory $\mathrm{T}$ cells favoring tumor growth. J Immunol. 2012;189: 5602-11.

42. Sica A, Bronte V. Altered macrophage differentiation and immune dysfunction in tumor development. J Clin Invest. 2007;117:1155-66.
43. Grizzle WE, Xu X, Zhang S, Stockard CR, Liu C, Yu S, Wang J, Mountz JD, Zhang HG. Age-related increase of tumor susceptibility is associated with myeloid-derived suppressor cell mediated suppression of $\mathrm{T}$ cell cytotoxicity in recombinant inbred BXD12 mice. Mech Ageing Dev. 2007;128:672-80.

44. Mocikat R, Braumuller H, Gumy A, Egeter O, Ziegler H, Reusch U, Bubeck A, Louis J, Mailhammer R, Riethmuller G, Koszinowski U, Rocken M. Natural killer cells activated by MHC class I(low) targets prime dendritic cells to induce protective CD8 T cell responses. Immunity. 2003;19:561-9.

45. Guerra N, Tan YX, Joncker NT, Choy A, Gallardo F, Xiong N, Knoblaugh S, Cado D, Greenberg NM, Raulet DH. NKG2D-deficient mice are defective in tumor surveillance in models of spontaneous malignancy. Immunity. 2008;28:571-80.

46. Smyth MJ, Thia KY, Street SE, Cretney E, Trapani JA, Taniguchi M, Kawano T, Pelikan SB, Crowe NY, Godfrey DI. Differential tumor surveillance by natural killer (NK) and NKT cells. J Exp Med. 2000;191:661-8.

47. Turner JG, Rakhmilevich AL, Burdelya L, Neal Z, Imboden M, Sondel PM, Yu H. Anti-CD40 antibody induces antitumor and antimetastatic effects: the role of NK cells. J Immunol. 2001;166:89-94.

48. Hallett WH, Ames E, Motarjemi M, Barao I, Shanker A, Tamang DL, Sayers TJ, Hudig D, Murphy WJ. Sensitization of tumor cells to NK cell-mediated killing by proteasome inhibition. J Immunol. 2008;180:163-70.

49. Castro F, Leal B, Denny A, Bahar R, Lampkin S, Reddick R, Lu S, Gravekamp C. Vaccination with Mage-b DNA induces CD8 T-cell responses at young but not old age in mice with metastatic breast cancer. Br J Cancer. 2009;101:1329-37.

50. Nakui M, Ohta A, Sekimoto M, Sato M, Iwakabe K, Yahata T, Kitamura H, Koda T, Kawano T,Makuuchi $\mathrm{H}$, Taniguchi M, Nishimura T. Potentiation of antitumor effect of NKT cell ligand, alpha-galactosylceramide by combination with IL-12 on lung metastasis of malignant melanoma cells. Clin Exp Metastasis. 2000;18:147-53.

51. Wakai Y, Matsui J, Koizumi K, Tsunoda S, Makimoto H, Ohizumi I, Taniguchi K, Kaiho S, Saito H, Utoguchi N, Tsutsumi Y, Nakagawa S, Ohsugi Y, Mayumi T. Effective cancer targeting 
using an anti-tumor tissue vascular endotheliumspecific monoclonal antibody (TES-23). Jpn J Cancer Res. 2000;91:1319-25.

52. Giaccone G, Punt CJ, Ando Y, Ruijter R, Nishi N, Peters M, von Blomberg BM, Scheper RJ, van der Vliet HJ, van den Eertwegh AJ, Roelvink M, Beijnen J, Zwierzina H, Pinedo HM. A phase I study of the natural killer T-cell ligand alpha-galactosylceramide (KRN7000) in patients with solid tumors. Clin Cancer Res. 2002;8:3702-9.

53. Provinciali M, Argentati K, Tibaldi A. Efficacy of cancer gene therapy in aging: adenocarcinoma cells engineered to release IL-2 are rejected but do not induce tumor specific immune memory in old mice. Gene Ther. 2000;7:624-32.

54. Provinciali M, Smorlesi A, Donnini A, Bartozzi B, Amici A. Low effectiveness of DNA vaccination against HER-2/neu in ageing., Vaccine. 2003;21:843-8.

55. Lustgarten J, Dominguez AL, Thoman M. Aged mice develop protective antitumor immune responses with appropriate costimulation. J Immunol. 2004;173:4510-5.

56. Sharma S, Dominguez AL, Lustgarten J. Aging affect the anti-tumor potential of dendritic cell vaccination, but it can be overcome by co-stimulation with anti-OX40 or anti-4-1BB. Exp Gerontol. 2006;41:78-84.

57. Grolleau-Julius A, Abernathy L, Harning E, Yung RL.Mechanisms of murine dendritic cell antitumor dysfunction in aging. Cancer Immunol Immunother. 2009;58:1935-9.

58. Kim SH, Castro F, Paterson Y, Gravekamp C. High efficacy of a Listeria-based vaccine against metastatic breast cancer reveals a dual mode of action. Cancer Res. 2009;69:5860-6.

59. Quispe-Tintaya W, Chandra D, Jahangir A, Harris M, Casadevall A, Dadachova E, Gravekamp C.
Nontoxic radioactive Listeriaat is a highly effective therapy against metastatic pancreatic cancer, Proc Natl Acad Sci U S A. 2013;110:8668-73.

60. Hiratsuka S, Watanabe A, Aburatani H, Maru Y. Tumour-mediated upregulation of chemoattractants and recruitment of myeloid cells predetermines lung metastasis. Nat Cell Biol. 2006'8:1369-75.

61. Lechner MG, Epstein AL. A new mechanism for blocking myeloid-derived suppressor cells by $\mathrm{CpG}$. Clin Cancer Res. 2011;17:1645-8.

62. Maletto B, Ropolo A, Moron V, Pistoresi-Palencia MC. CpG-DNA stimulates cellular and humoral immunity and promotes Th1 differentiation in aged BALB/c mice. J Leukoc Biol. 2002;72:447-54.

63. Singh M, Ramos I, Asafu-Adjei D, Quispe-Tintaya W, Chandra D, Jahangir A, Zang X, Aggarwal BB, Gravekamp C. Curcumin improves the therapeutic efficacy of Listeria(at)-Mage-b vaccine in correlation with improved $\mathrm{T}$-cell responses in blood of a triple-negative breast cancer model 4T1. Cancer Med. 2013;2:571-82.

64. Stacy S, Infante AJ, Wall KA, Krolick K, Kraig E. Recall immune memory: a new tool for generating late onset autoimmune myasthenia gravis. Mech Ageing Dev. 2003;124:931-40.

65. Tan JT, Dudl E, LeRoy E, Murray R, Sprent J, Weinberg KI, Surh CD. IL-7 is critical for homeostatic proliferation and survival of naive T cells, Proc Natl Acad Sci USA. 2001;98:8732-37.

66. Patyar S, Joshi R, Byrav DS, Prakash A, Medhi B, Das BK. Bacteria in cancer therapy: a novel experimental strategy. J Biomed Sci. 2010;17:21.

67. Yu YA, Shabahang S, Timiryasova TM, Zhang Q, Beltz R, Gentschev I, Goebel W, Szalay AA. Visualization of tumors and metastases in live animals with bacteria and vaccinia virus encoding lightemitting proteins. Nat Biotechnol. 2004;22:313-20. 